\title{
Federal, provincial and territorial public health response plan for biological events
}

\author{
R McNeill' , J Topping ${ }^{1 \star}$ on behalf of the FPT Response Plan Task Group
}

\begin{abstract}
The Federal/Provincial/Territorial (FPT) Public Health Response Plan for Biological Events was developed for the Public Health Network Council (PHNC). This plan outlines how the national response to public health events caused by biological agents will be conducted and coordinated, with a focus on implementation of responses led by senior-level FPT public health decision-makers. The plan was developed by an expert task group and was approved by PHNC in October, 2017. The plan describes roles, responsibilities and authorities of FPT governments for public health and emergency management, a concept of operations outlining four scalable response levels and a governance structure that aims to facilitate an efficient, timely, evidence-informed and consistent approach across jurisdictions. Improving effective engagement amongst public health, health care delivery and health emergency management authorities is a key objective of the plan.
\end{abstract}

Affiliation

${ }^{1}$ Centre for Emergency Preparedness and Response, Public Health Agency of Canada, Ottawa, ON ^Correspondence: HPOC_
COPS@phac-aspc.gc.ca

Suggested citation: McNeill R, Topping J. Federal, provincial and territorial public health response plan for biological events. Can Commun Dis Rep. 2018;44(1):1-5.

https://doi.org/10.14745/ccdr.v44i01a01

\section{Introduction}

Emerging infections, and other biological events, happen regularly in Canada and around the world, and require a coordinated health and public health response. Previous public health responses at a national level in Canada have addressed many hazards, ranging from epidemics of novel respiratory pathogens (e.g., SARS and H1N1 pandemics), to emerging infections, such as international and travel-related public health threats (e.g., Zika and Ebola), food-borne illness outbreaks, significant vaccine supply issues and the current opioid crisis.

Health planners have learned a great deal from previous experiences. The $2009 \mathrm{H} 1 \mathrm{~N} 1$ pandemic revealed that coordination of decision-making and information sharing at the federal/provincial/territorial (FPT) level was often complex, challenging and time consuming; for example, multiple levels of government provided similar, but not identical, advice and recommendations regarding clinical guidelines for front-line health professionals and these differences led to confusion about whose advice to follow (1).

Lessons learned have demonstrated the need for a nimble, flexible FPT governance structure that can be applied consistently, in whole or in part, to a range of public health scenarios. They also demonstrated the need to clarify roles and responsibilities, as well as decision-making and approval processes, at various levels of government within the health sector. To address these issues, FPT Deputy Ministers of Health agreed that improvements to the FPT governance structure developed during $\mathrm{H} 1 \mathrm{~N} 1$ should continue, with the understanding that they would need to be flexible enough to adapt to different types of urgent situations, while respecting various responsibilities and authorities.

Public health in Canada is a shared responsibility among municipal, provincial, territorial and federal governments. Significant public health events, including public health emergencies, require coordination between all levels of government and a consistent approach across jurisdictions. Consensus on response strategies at a national level is desirable, recognizing that some or all jurisdictions involved (e.g., local, FPT governments and others) may choose to implement actions dependent on the legislative frameworks and circumstances of the event. It was with this goal of facilitating collaboration and decision-making between multiple authorities and levels of government, that the FPT Public Health Response Plan for Biological Events was developed.

Legislation requires all jurisdictions in Canada have plans that set out the steps to be taken in the event of an emergency. These plans identify linkages and channels of communication to other ministries, programs and agencies of the government and contribute to a coordinated, system-wide approach to emergency management. In addition, the FPT health sector has in place well established hazard-specific tools that are routinely used to effectively plan and manage public health events. A feature of the FPT Public Health Response Plan for Biological Events is that it is intended to complement and, where appropriate, be used in conjunction with existing mechanisms. For example, the Canadian Pandemic Influenza Preparedness: Planning Guidance for the Health Sector (CPIP) provides pan-Canadian planning guidance for pandemic influenza (2). 
In a pandemic, it is expected the CPIP will inform the technical aspects of the response while the FPT Public Health Response Plan for Biological Events will provide the overall governance structure that will support decision-making. The objective of this paper is to provide a high level summary of the FPT Public Health Response Plan for Biological Events.

\section{Key features of the plan}

The plan is made up of a main body and various supporting appendices. The main body includes two key components: the concept of operations and the FPT governance structure. It also addresses health care sector engagement, describes how the governance structure will be supported and how it will interact with both federal and PT operations centres. The appendices include the guiding principles used in the development of the plan, a summary of key FPT roles and responsibilities for public health and emergency management and the Terms of Reference for the various groups within the governance structure.

\section{Concept of operations}

The concept of operations describes the steps that are taken from the initial notification of a public health event leading to the activation of the plan to the eventual de-escalation of the response. It describes how notification of public health events are made to the Public Health Agency of Canada (PHAC), and how response needs are assessed by technical experts and decision-makers. The concept of operations also describes four response levels to facilitate scaling of response activities as needed. Examples of scenarios where these response levels may be applied are given below.

- Routine: There is a need for information sharing regarding a public health event between an affected jurisdiction and other FPT or international authorities (e.g., outbreak of measles in a single jurisdiction).

- Heightened: There is a need for a routine public health response involving one or more jurisdictions (e.g., a food-borne outbreak occurring in multiple jurisdictions).

- Escalated: A coordinated response is required for a public health event that has potential implications for the Canadian health care system (e.g., outbreak due to a highly antibiotic-resistant bacterium).

- Emergency: A national response is required for an event in Canada causing significant illness and has the potential for rapid spread (e.g., a novel influenza virus is spreading efficiently between humans).

\section{Governance structure}

The governance structure is designed to streamline response processes, provide clarity on roles/responsibilities, facilitate a high degree of situational awareness and centralize risk management and task delegation. It is modelled on the 'dayto-day' governance structures of the Public Health Network Council and is made up of a Special Advisory Committee (SAC) and three main response streams (technical, logistical and communications) each led by advisory committees/working groups. The governance structure, through the SAC, reports to and is accountable to the FPT Conference of Deputy Ministers of Health $(\mathrm{CDMH})$.

\section{Special Advisory Committee}

The SAC has a mandate to provide advice to the $\mathrm{CDMH}$ pertaining to the coordination, public health policy and technical content on matters related to the response to a significant public health event. As such, SAC is the main decision-making body of the governance and the main forum for approval of products developed by the governance such as recommendations, guidance documents, protocols and communication products. The SAC is composed of the members of the Pan-Canadian Public Health Network Council and the Council of Chief Medical Officers of Health (CCMOH).

\section{Technical Advisory Committee}

The Technical Advisory Committee (TAC) is largely focused on the characteristics of the public health event and what needs to be done from a technical, public health perspective to achieve the response objectives. Under TAC, task groups will be established to address public health response functions (e.g., surveillance, laboratory and medical countermeasures) and to provide technical input into products such as communications material aimed at informing media, health professionals and the public on the most current information available at the time. The TAC will develop products such as epidemiological reports, guidance on public health measures, and recommendations on the type of medical countermeasures (e.g., medications/antivirals or vaccines) to be used. The TAC will be co-chaired by the co-chairs of the Communicable and Infectious Disease Steering Committee (CID-SC).

\section{Public Health Network Communications Group}

The Public Health Network Communication Group (PHN CG) supports consistent and coordinated public communications by providing a mechanism by which FPT governments work together on common messaging. It provides a forum to share news releases and media material, conduct technical and media briefings, and direct Canadians on where to seek the most current information and guidance. Once the plan is activated, communication related response activities will be coordinated through the PHN CG, thus enabling FPT governments to align their communication strategies.

\section{Logistics Advisory Committee}

The Logistics Advisory Committee (LAC) will be largely focused on how the response activities will be implemented in order to achieve the response objectives. As with the TAC, under the LAC, task groups may be established to address specific logistical response issues. For example, LAC is responsible for engaging with the health care delivery sector and for establishing task groups as required to ensure this sector is represented in the governance. The LAC would develop products such as funding agreements, mutual aid agreements and recommendations regarding acquiring resources (e.g., vaccines or other medical countermeasures). The LAC is co-chaired by the co-chairs of the Public Health Infrastructure Steering Committee (PHI-SC). 


\section{Health care delivery engagement}

Decisions of interest to health care clinicians are expected to be made at various fora in the governance structure. For example, the LAC may activate a Health Care Delivery Engagement Task Group to respond to requests by the SAC for products such as guidance documents. Task group members would include federal representatives and multidisciplinary experts, and provincial/territorial representatives that would also provide their perspective and expertise, including clinical expertise. The Task Group would engage non-governmental organizations, research communities and other stakeholders in the area of health care delivery. It would also coordinate with external expert organizations, such as the Association of Medical Microbiology and Infectious Disease (AMMI) Canada, to foster linkages between public health technical and response products and health care related products such as clinical care guidelines. The TAC would also establish task groups in this same fashion to help inform development of technical guidance and recommendations including those aimed at health professionals.

Health care delivery is further represented at a strategic level by SAC members who act as informal liaisons to the health care sector within their respective jurisidictions, and provide their unique jurisdictional views to SAC to ensure that the full continuum of the health sector is considered in response planning. Complementary to this, at the operational level, the health emergency management directors of provincial/ territorial ministries of health may assume various roles within the governance structure and would act as liaisons to health care delivery within their jurisdiction as well.

\section{Governance support}

\section{SAC Secretariat}

The SAC Secretariat supports the SAC and the response streams by assuming multiple coordination functions. It is responsible for rapid centralized analysis of issues and response needs, prioritization and distribution of tasks. Specifically the SAC Secretariat, with direction from SAC co-chairs, will identify what type of product/action is required, task this to the appropriate groups (TAC, LAC or Communications) within the governance structure and monitor progress.

Another key activity of the SAC Secretariat is to consider the integration of analysis and evidence across the response streams, including policy implications on decisions related to a public health event. An example of when this would occur is if SAC requested a single product that includes technical recommendations, logistical issues and a communication response-such as a vaccine response strategy. In order to support effective decision-making by SAC, there is a need to ensure that all evidence is considered in a holistic manner, informed by the co-chairs of the relevant response streams.

\section{Health Portfolio Operations Centre}

Figure 1 outlines the FPT governance structure and illustrates the operational communications between the federal Health Portfolio Operations Centre (HPOC) and provincial/territorial Emergency Operations Centres (EOCs). The HPOC serves as the Health Portfolio focal point for the coordination of response activities to significant public health events of national interest within the Health Portfolio's mandate, and acts as the point of contact for operational communications with other government departments and internationally. When the plan is activated, the HPOC provides support to the governance structure and participates in its groups as required.

\section{Figure 1: FPT governance structure and its relation to FPT operation centres}

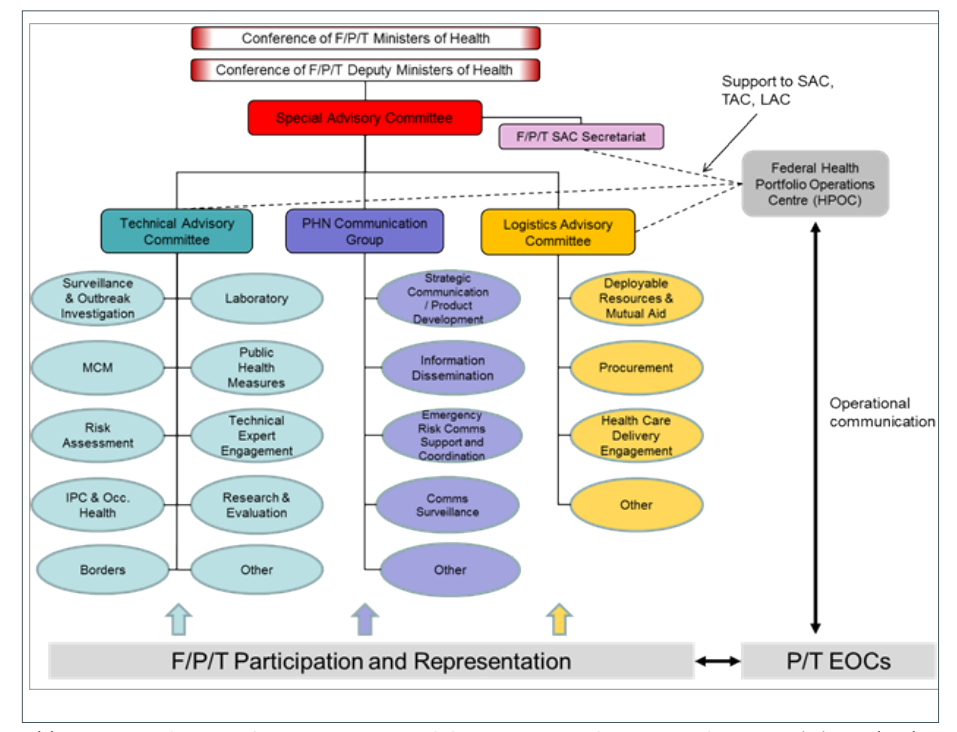

Abbreviations: Comms, Communications; EOCs, Emergency Operations Centres; F/P/T, Federal provincial territorial; IPC\&Occ Health, Infection Prevention Control and Occupational Health; LAC Logistics Advisory Committee; MCM, Medical Counter-measures; PHN, Public Health Network; SAC, Special Advisory Committee; TAC, Technical Advisory Committee

\section{Discussion}

The FPT Public Health Response Plan for Biological Events, as all response plans, is an evergreen document. The need for revision will be guided by after action reviews following the response to a real or simulated event requiring implementation of the plan, in whole or in part. The revision of the plan may also include recommendations for the development of new event-specific Annexes as required, to further support implementation of the plan. Implementation will also be supported by training and exercises to familiarize various stakeholders with roles and responsibilities under the plan, and to identify areas for further improvement.

\section{Conclusion}

The FPT Public Health Response Plan for Biological Events is an important new tool that will help to support inter-jurisdictional collaboration, information-sharing and decision-making between and amongst various jurisdictions. It represents a continuing commitment on behalf of FPT governments to work collaboratively to ensure Canada is ready to respond to public health events and prepared to protect the health of Canadians.

\section{Conflict of interest}

None. 


\section{Acknowledgements}

Special thanks to the Task Group who developed the plan (see Appendix A for membership) and to the Task Group co-chairs Dr. Howard Njoo of the Infection Prevention and Control Branch of PHAC and John Lavery of Health Emergency Management British Columbia-their leadership and commitment to this project has been instrumental in the completion of this significant piece of work. We also thank the following individuals for their valued contribution to the plan: J Sciberras, L Menard and JF Duperré.

\section{References}

1. Public Health Agency of Canada and Health Canada. Lessons Learned Review: Public Health Agency of Canada and Health Canada Response to the 2009 H1N1 Pandemic. Ottawa (ON): PHAC; 2010. http://www.phac-aspc.gc.ca/about_ apropos/evaluation/reports-rapports/2010-2011/h1n1/pdf/ h1n1-eng.pdf

2. Public Health Agency of Canada. Canadian Pandemic Influenza Preparedness: Planning Guidance for the Health Sector. Ottawa (ON): PHAC; 2015. https://www.canada.ca/ en/public-health/services/flu-influenza/canadian-pandemicinfluenza-preparedness-planning-guidance-health-sector. html

\section{Appendix A: Members of the FPT Response Plan Task Group}

\section{Thomas Appleyard}

Manager: Training, Exercises \& Awareness (A)

Emergency Management Branch

Population and Public Health Division

Ministry of Health and Long-Term Care

Toronto ON

\section{Tamela Carroll}

Senior Program Advisor

New Brunswick Department of Health

Office of the Chief Medical Officer of Health Communicable

Disease Branch

Fredericton NB

\section{Jean-François Duperré}

A/Executive Director

Center for Emergency Preparedness and Response

Public Health Agency of Canada

Ottawa ON

\section{Kelly Folz}

Manager

Intergovernmental Affairs

Intergovernmental and Stakeholder Policy Division

Public Health Agency of Canada

Ottawa ON

\section{Mélanie Goulette Nadon}

Senior Communications Advisor

Public Health Strategic Communications Directorate

Communications and Public Affairs Branch

Health Canada

Ottawa ON

\section{Dr. Karen Grimsrud}

Chief Medical Officer of Health

Office of the Chief Medical Officer of Health

Edmonton AB

\section{Steve Guercio}

Executive Director

National Microbiology Laboratory

Infectious Disease Prevention and Control Branch

Public Health Agency of Canada

Winnipeg MB

\begin{abstract}
Jason Letto
Manager

Health Emergency Management Program

Department of Health and Community Services

Government of Newfoundland and Labrador
\end{abstract}

\section{Garnet Matchett}

Director of Operations

Health Emergency Management Unit

Saskatchewan Ministry of Health

Regina SK St. John's NL

\section{Robin McNeill}

Sr. Emergency Management Planner

Office of Situational Awareness and Operations

Centre for Emergency Preparedness and Response

Health Security and Infrastructure Branch

Public Health Agency of Canada

Ottawa ON

Dr. Howard Njoo (Co-Chair)

Deputy Chief Public Health Officer

Office of the Chief Public Health Officer

Public Health Agency of Canada

Ottawa ON

Gary O'Toole

Director, Public Health

Nova Scotia Health Authority, Northern Zone

Colchester East Hants Health Centre

Truro NS

\section{Dr. Katarina Pintar}

Manager, Policy Integration Division

Centre for Food-Borne, Environmental and Zoonotic Infectious

Diseases

Infectious Disease Prevention and Control Branch

Public Health Agency of Canada

Ottawa ON

Dr. Barry N. Pakes

Deputy Chief Medical Officer of Health (acting)

Department of Health, Government of Nunavut

PO Box 1000, Station 1000

Iqaluit NU 


\section{Appendix A: Members of the FPT Response Plan Task Group (continued)}

\author{
Alternate \\ Dr. Cindi Corbett \\ Director, Bacterial Pathogens Division \\ National Microbiology Laboratory \\ Infectious Disease Prevention and Control Branch \\ Public Health Agency of Canada \\ Winnipeg MB

\section{Erin Henry} \\ Director \\ Communicable Disease Control Division \\ Office of Population and Public Health \\ Population Health and Primary Care Directorate \\ First Nations and Inuit Health Branch \\ Health Canada \\ Ottawa ON

\section{Alternate} \\ Fanie Lalonde \\ National Program Manager \\ Communicable Disease Emergencies/Infection Prevention \& \\ Control Program \\ Office of Population \& Public Health \\ Population Health and Primary Care Directorate \\ First Nations and Inuit Health Branch \\ Health Canada \\ Ottawa ON

\section{Althea House} \\ Manager Seasonal and Pandemic Influenza \\ Centre for Immunization and Respiratory Infectious Diseases \\ Infectious Disease Prevention and Control Branch \\ Public Health Agency of Canada \\ Ottawa ON \\ John Lavery (Co-Chair) \\ Executive Director \\ Health Emergency Management British Columbia \\ 2nd Floor-1770 West 7th Avenue \\ Vancouver BC

\section{Alternate} \\ Kathryn Forge \\ Director, Emergency Management Unit \\ Health Emergency Management, British Columbia \\ Vancouver BC
}

Dr. Michel Savard

Médecin conseil

Direction générale de santé publique

Ministère de la Santé et des Services sociaux

Montréal QC

Jill Sciberras

Nursing Advisor

Centre for Emergency Preparedness and Response

Public Health Agency of Canada

Toronto ON

\section{Dr. Saqib Shahab}

Government of Saskatchewan

Chief Medical Health Officer

Ministry of Health, Population Health Branch

Regina SK

\section{Mariyam Syed}

Emergency Management Analyst

Public Health and Compliance Division

Health Protection Branch

Alberta Ministry of Health

Edmonton $\mathrm{AB}$

John Topping

Director

Office of Situational Awareness and Operations

Centre for Emergency Preparedness and Response

Public Health Agency of Canada

Ottawa ON

Dr. Elise Weiss

Acting Chief Provincial Public Health Officer

Manitoba Health, Seniors and Active Living

Government of Manitoba

4004-300 Carlton Street

Winnipeg MB

Judith Wood Bayne

Regional Director - Atlantic Region

Health Promotion and Chronic Disease Prevention Branch

Public Health Agency of Canada

Halifax NS

Alternate

Lise Gauthier

Regional Coordinator Emergency Management Unit- Québec Health Promotion and Chronic Disease Prevention Branch

Public Health Agency of Canada

Montreal QC 